\title{
Near-Death Experiences and Healing
}

To the Editor:

Recently I was going through my collection of near-death experiences (NDEs) for the sake of a fellow researcher when I noticed for the first time that four experiencers had voluntarily said that after the experience they felt cured of, or gained relief from, the physical illness from which they were suffering at the time. Because these cases were collected several years ago, I am unable to trace the experiencers and verify their claims. The claims, however, do raise the question whether an NDE can cure physical illness.

This appears to be an aspect of the NDE that has so far not drawn the attention of researchers, one that I think merits serious study. If it is confirmed that the NDE, or certain elements of the experience, can bring about cure or relief, we might try to identify the underlying mechanism; this could have many practical applications. I will pre- 
sent here the four cases from my collection and explain why I think NDEs may influence the course of physical illness.

The first NDEr, the wife of a farm laborer, who was ill with high fever for several days, became unconscious and was assumed to be dead. As the body was being placed on a bamboo stretcher to be carried to the cremation ground, someone noticed her eyelids move briefly. Soon after, the woman regained full consciousness, sat up, and, to everybody's surprise, said that she felt better and she had no fever. A few days later she told her husband what she experienced during the period she was thought dead.

She was standing probably in a rice field when two dark and menacing figures appeared suddenly, one in front of her and the other behind her. She found herself following the man in front. After a while she felt foolish going with complete strangers, and after some hesitation asserted that she would not go one step further unless they told her who they were and where they were taking her. At this point she became conscious.

The second experiencer, who was bedridden due to a severe attack of influenza, felt one morning that he had risen several hundred feet above the ground and was floating along amidst fluffy white clouds. At some stage he found himself on a "powder blue" island where the flora and fauna were of "wonderful colors," "just the right colors." He then found himself walking along with a venerable sage-like person who spoke about something very profound. They were together for a long time. The experiencer understood everything the other man said, but on recovery he was unable to recall any of it. It was, he said, "in my mind-in the subconscious-somewhere, only I cannot say it in words."

According to this experiencer, he recovered from his illness far more quickly than from previous attacks despite it being winter. $\mathrm{He}$ suggested that the reason could have been some medicine his doctor had administered; however, he preferred to think that his experience assisted his recovery. "Somehow I feel my hallucination did me a power of good-that gentle old sage in my hallucination speaking to me softly and unhurriedly-reassuring me-that could be an important factor."

The third subject was in the hospital for treatment of "high fever and congestion in the lungs." One afternoon he felt he was bodily 
rising in the air from his bed. As he did so, he felt "blissful" or euphoric. He kept on rising and at some stage found himself looking down at a vast, blue, calm lake or ocean. He wished to be in that state of mind indefinitely. Some time later he became conscious. According to the subject, he recovered very rapidly after this NDE, and his doctor, who had judged him to be a very severe case, was astonished at his rate of progress.

The fourth subject was walking up a hill with his wife and son when he felt giddy and began to sweat profusely. He lay down on the ground and soon became unconscious. After a while he recovered and they had tea snacks they had brought with them. The experiencer then told his wife that he was quite fit to continue their climb, but she insisted they return.

When he was lying on the ground he had undergone an out-of-body experience $(\mathrm{OBE})$. The affective background was not joy or ecstasy but "a sense of detachment-neutrality-well, the kind of attitude that in our [Hindu] tradition is said to provide true happinessnonattachment . . . . It is a positive feeling. That I think did a good deal to refresh me . . . I I felt full of energy on coming out of the OBE ... [like] your batteries [had been] recharged.”

Assuming that these NDErs' claims of rapid recovery are correct, what could be the explanation? It seems to me that the process involved is likely to be similar to that set in motion by psychological techniques such as relaxation and visualization exercises. These methods, which are part of the emerging discipline of psychoneuroimmunology, are found to help cure disease by strengthening the immune system or causing the release of endogenous chemicals (Ader, 1981).

In the second and third examples of NDEs cited above, the imagery experienced-a vast calm body of water and a powder-blue island with colorful flora and fauna; a leisurely walk with a gentle, venerable person speaking reassuringly-and the accompanying calm and blissful affects are likely to have exerted a beneficial influence. It is especially noteworthy that the second subject emphasized the role of pleasant imagery.

In the first example, the imagery was not pleasant: two dark menacing persons were forcing the experiencer to go with them. But her firm decision not to go further with them could be an indication of her determination to get well, which could have contributed to her 
recovery from her illness. Her recovery, it may be noted, was almost instantaneous. It appears that such quick healing can take place, and it can be explained in naturalistic terms. Cyril Smith and Simon Best (1990) have suggested some possible mechanisms underlying instantaneous cures.

In the fourth example cited above, which is an OBE, the subject did not see any paradisiacal imagery, but the affective accompaniment was so markedly positive that he was convinced it not only helped him recover but also rendered him energetic enough to resume his climb.

I am not suggesting from these cases that recovery from physical illness necessarily follows the NDE. The number of examples of recovery is too small to permit such a conclusion. In fact, of the nine NDE accounts in my collection that involved illness at the time of the experience, in only four was there a claim of cure or relief. It is possible that NDEs can cure only certain types of diseases, not all.

Furthermore, I know of at least one instance of an NDEr who did not seem to benefit physically from her experience. The elderly subject, who had had diabetes for a long time, became unconscious for about fifteen minutes, during which she saw a vast expanse of blue and felt ineffable peace and well being. From the way she spoke about her NDE, she was profoundly impressed by it; and yet, so far as I could ascertain, she did not have even temporary relief from her diabetes, and she suffered from it until her death four years later. Thus the examples I have cited should be regarded as only suggesting the need for in-depth investigation of reports of curative or palliative effects of NDEs.

\section{References}

Ader, R. (Ed.). (1981). Psychoneuroimmunology. Orlando, FL: Academic Press. Smith, C., and Best, S. (1990). Electromagnetic man. London, England: Dent.

V. Krishnan

Post Box 1863

Ramakrishna Sevasram

Kaloor

Cochin 682017

India 